\title{
Experimental determination of restitution coefficient of garlic bulb based on high-speed photography
}

\author{
Zhaoyang $\mathrm{Yu}^{1,2}$, Zhichao $\mathrm{Hu}^{2}$, Baoliang Peng ${ }^{2}$, Fengwei $\mathrm{Gu}^{2}$, Ling Yang ${ }^{1}$, Mingjin Yang ${ }^{1 *}$ \\ (1. College of Engineering and Technology, Southwest University, Chongqing 400715, China; \\ 2. Nanjing Institute of Agricultural Mechanization, Ministry of Agriculture and Rural Affairs, Nanjing 210014, China)
}

\begin{abstract}
Restitution coefficient (RC) of garlic bulb is an important mechanical property that is required to establish the kinematics model of bulb collision and research the damage mechanism of bulb collision. In this study, kinetic equations of bulb collision were established based on Hertz's contact theory. The kinematics characteristics, elastoplastic deformation and contact damage during bulb collision were analyzed by using high-speed photography. The effects of bulb mass, moisture content, collision material, material thickness and release height on the RC were investigated by mixed orthogonal experiments and single-factor experiments. The results showed that the movement of bulb in the compression stage was translation, and the movement in the rebound stage was translation and rotation. During collision, the larger the rotational angular velocity of the bulb was, the smaller the measured RC would be. The contact damage of bulb included internal damage of the tissue, epidermis stretch and tear. The significance of effects of factors on RC decreased with the following sequence: collision material, release height, material thickness, bulb mass, and moisture content. Collision material, release height, material thickness, and bulb mass were significant factors. The RC between the bulb and Q235, nylon, and rubber decreased sequentially. The RC decreased with the increase of release height and bulb mass. The RC increased with the increase of material thickness of Q235, while it decreased with the increase of material thickness of rubber or Nylon. The determination coefficients of the regression equations between the significant factors and the RC were all greater than 0.96 . The results will be helpful for damage mechanism analysis and design of garlic production equipment.
\end{abstract}

Keywords: garlic bulb, collision, restitution coefficient, high-speed photography, experimental tests

DOI: $10.25165 /$ j.jjabe.20211402.5882

Citation: Yu Z Y, Hu Z C, Peng B L, Gu F W, Yang L, Yang M J. Experimental determination of restitution coefficient of garlic bulb based on high-speed photography. Int J Agric \& Biol Eng, 2021; 14(2): 81-90.

\section{Introduction}

Garlic (Allium sativum L.) is planted worldwide, and its bulbs contain many health benefits, especially allicin, which determines the garlic's characteristic scent and flavor. Garlic is indispensable for certain dishes and cuisines, such as Chinese garlic scent eggplant, France aioli sauce, Italian anchovy dip, etc. A garlic bulb is composed of 4-35 cloves, and the epidermis of the bulb and its cloves are thin and tender. During processes of mechanized sowing $^{[1]}$, harvesting ${ }^{[2]}$ and transporting ${ }^{[3]}$, the collision between the bulb and components of machines are unavoidable, which can easily cause mechanical damage to garlic bulb ${ }^{[4]}$. Mechanical damage can reduce the production and quality of garlic, cause economic losses of garlic industry, and has been the main factor that restricts the development of garlic mechanized production.

Collision is the main cause of mechanical damage ${ }^{[5,6]}$. Restitution coefficient (RC) is an important mechanical property

\section{Received date: 2020-05-01 Accepted date: 2020-09-20}

Biographies: Zhaoyang Yu, PhD candidate, Assistant Professor, research interests: agricultural mechanization engineering, Email: 99yzy99@163.com; Zhichao Hu, PhD, Professor, research interests: agricultural mechanization engineering, Email: zchu369@163.com; Baoliang Peng, Professor, research interests: agricultural mechanization engineering, Email: 734392925@qq.com; Fengwei Gu, Professor, research interests: agricultural mechanization engineering, Email: 409851459@qq.com; Ling Yang, PhD, Professor, research interests: agricultural mechanization engineering, Email: 857540348@qq.com.

*Corresponding author: Mingjin Yang, PhD, Professor, research interests: agriculture machine and equipment engineering. College of Engineering and Technology, Southwest University, Chongqing 400715, China. Tel: +86-23-68251265, Email: ymingjin@swu.edu.cn. that is required to simulate the kinematics and kinetics characteristics of agriculture material during collision using discrete element method (DEM) $)^{[7]}$ and finite element method $(\mathrm{FEM})^{[8,9]}$ and research the damage mechanism of collision. Garlic bulb is viscoelastic ${ }^{[10]}$. During collision, the bulb undergoes elastoplastic deformation, bounce and rotation around the center of gravity, accompanied by energy conversion and dissipation ${ }^{[11,12]}$. $\mathrm{RC}$ is the ratio of the incidence velocity to reflection velocity, which can directly reflect the ability to restore to the original state after collision ${ }^{[13]}$. The larger the RC of garlic bulb is, the better the elasticity will be, and the stronger the recovery ability will be after collision. In addition, RC can represent the energy dissipation during collision ${ }^{[14]}$. The larger the RC of garlic bulb is, the less the energy consumption will be during collision. The RC of garlic bulb is not only related to its own physical characteristics but also related to the factors such as collision material and incidence velocity. Then, an appropriate $\mathrm{RC}$ of the garlic bulb is required for mechanized operation in practice.

The research methods of RC mainly include theoretical derivation, similarity model test, and bench test. Lately, many publications of researches on RC of different materials were available. For example, Wang et al. ${ }^{[15,16]}$ established theoretical models of RC of maize grain based on Stronge's impact mechanics model and Newton-Euler dynamic equations, and studied the kinematics characteristics of maize grain during collision. The results showed that maize grain underwent deformation, translation, and rotation around the center of gravity during collision. Qin et al. ${ }^{[17]}$ established kinetics equations of collision process based on 
$\mathrm{RC}$, by combining dynamic contact theory with classical collision theory, and proved that the $\mathrm{RC}$ represented energy dissipation of the collision. Dintwa et al. ${ }^{[18]}$ studied the dynamic process of the collision between apple and rigid walls, and found that the $\mathrm{RC}$ was a common measure of energy dissipation of the collision and the $\mathrm{RC}$ of apple decreased nonlinearly with the increase of the incidence velocity. Aryaei et al. ${ }^{[19]}$ studied the RC of ball and energy dissipation of the collision based on FEM and bench test. The results showed that plastic deformation was one of the main causes of energy loss. Wong et al. ${ }^{[20]}$ and Marroquín et al. ${ }^{[21]}$ determined the RC between the granular material and the wall, using high-speed photography to record the granular material drop, collision, and rebound, and using image analysis to obtain the initial height, rebound height, and collision time of the granular material. The results showed that high accuracy of collision data was obtained by high-speed photography. Gómez et al. ${ }^{[22]}$ determined the $\mathrm{RC}$ of biomass pellets by using the pendulum method, and found that the rotation of biomass pellets during collision affected the RC. Mangwandi et al. ${ }^{[23]}$ studied the RC of granular materials in different incidence velocity, and found that the RC decreased with the increase of incidence velocity. Buzzi et al. ${ }^{[24]}$ conducted collision test by pouring concrete blocks of different shapes, and studied the effects of impact angles, initial rotational kinetic energy and block shapes on the RC of concrete blocks. Wang et al. ${ }^{[25]}$ found that collision material, release height and material thickness had significant effects on the RC of wheat and rapeseed. Feng et al. ${ }^{[26]}$ found that collision material, release height, tuber mass, and moisture content had significant effects on the RC of potato tuber. Nevertheless, to the best knowledge of the author, there are no publications of researches on collision process and RC of garlic bulb available.

In this study, the kinetics equations of garlic bulb collision were established based on Hertz's contact theory. The definition method of Newton RC was used to build the test platform of RC of garlic bulb collision. By combining with high-speed photography, the kinematics characteristics, elastoplastic deformation and contact damage during bulb collision were analyzed, the RC of garlic bulb collision was determined, the significant level of various factors that affected the RC was studied, and a regression model was established, which can provide data support for the optimization design of operating components of machines to alleviate damage to garlic bulbs.

\section{Theory}

\subsection{Contact theory of garlic bulb collision}

The kinematics model of the garlic bulb collision process based on free fall is shown in Figure $1^{[27]}$, by assuming that the bulb does not undergo relative slip with the collision plate during the collision, and the bulb is regarded as a sphere with uniform mass. $A$ is the initial point of collision between the bulb and the collision plate. $O$ is the transition point from the compression stage to the rebound stage. At this time, the relative velocity of the bulb is 0 , and the elastic deformation of bulb is the largest. $B$ is the point where the bulb breaks away from the collision plate. $A O$ is the compression stage. $O B$ is the rebound stage.

The garlic bulb is viscoelastic. The collision process between the bulb and the collision plate is an elastoplastic collision. As shown in Figure 1, $A O$ is shown as compression stage, the bulb and collision plate is compressed each other. The deformation of bulb in compression stage undergoes elastic stage and yield stage successively. With increase of deformation of the bulb, the contact force increases gradually at elastic stage. Due to the irreversible plastic deformation of the bulb at the yield stage, while the contact force reaches the maximum value, the compression deformation of the bulb continues to increase and the contact force decreases gradually ${ }^{[27]}$. When the compression deformation reaches the maximum value, the relative velocity of the bulb is 0 . Then the bulb enters the rebound stage $O B$ and moves away from the collision plate gradually, the compression deformation restitutes gradually, the contact force decreases gradually.

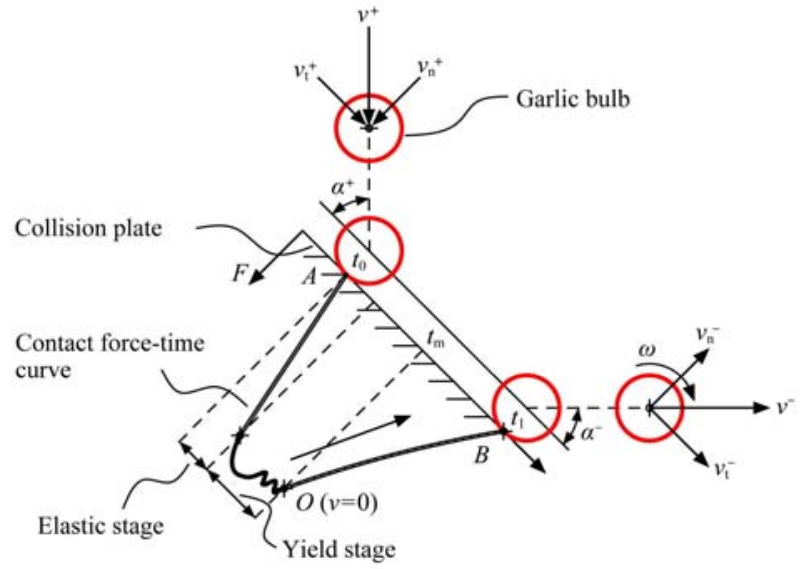

Note: $F$ is the contact force between bulb and collision plate, $\mathrm{N} ; t$ is the collision time, $\mathrm{s} ; v^{+}$is the incidence velocity of bulb, $\mathrm{m} / \mathrm{s} ; v_{\mathrm{t}}^{+}$is the tangential velocity of $v^{+}, \mathrm{m} / \mathrm{s} ; v_{\mathrm{n}}^{+}$is the normal velocity of $v^{+}, \mathrm{m} / \mathrm{s} ; v^{-}$is the reflection velocity of bulb, $\mathrm{m} / \mathrm{s} ; v_{\mathrm{t}}^{-}$is the tangential velocity of $v^{-}, \mathrm{m} / \mathrm{s} ; v_{\mathrm{n}}{ }^{-}$is the normal velocity of $v^{-}, \mathrm{m} / \mathrm{s}$; $\omega$ is the angular velocity of bulb, $\mathrm{rad} / \mathrm{s} ; \alpha^{+}$is the angle of incidence, $\left({ }^{\circ}\right) ; \alpha^{-}$is the angle of reflection, $\left(^{\circ}\right) ; t_{0}$ is the initial time of contact, $\mathrm{s} ; t_{\mathrm{m}}$ is time when the velocity of bulb is $0, \mathrm{~s} ; t_{1}$ is the time of rebound end, $\mathrm{s} ; A$ is the initial point of collision; $B$ is the end point of the collision; $O$ is the transition point from the compression stage to the rebound stage.

Figure 1 Kinematics model of garlic bulb collision process

\subsection{Kinetics equations of garlic bulb collision}

Hertz contact theory is the theoretical basis for studying the mechanics of collision contact. In order to meet Hertz contact theory ${ }^{[28]}$, the following assumptions are made: the bulb and the collision plate are considered as elastic half-space; the friction of contact surface is small and it is negligible. Figure 2 shows a schematic of the contact collision between the bulb and the collision plate.

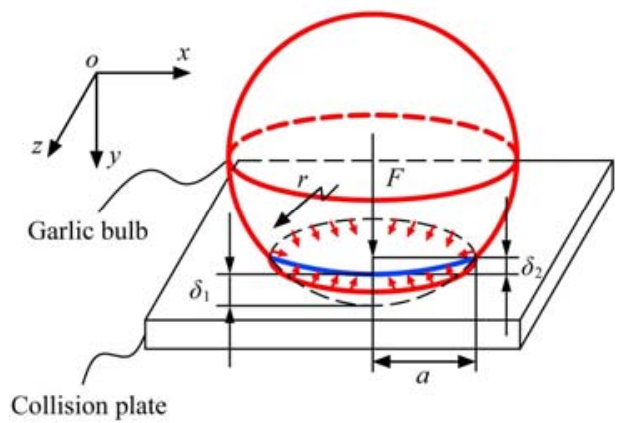

Note: $O-x y z$ is the space rectangular coordinate system. The blue line is the interface between the bulb and the collision plate during the deformation process. $r$ is the radius of garlic bulb, $\mathrm{m} ; a$ is the radius of contact circle, $\mathrm{m} ; \delta_{1}$ is the compression of the bulb, $\mathrm{m} ; \delta_{2}$ is the compression of the collision plate, $\mathrm{m}$.

Figure 2 Schematic of the contact collision between garlic bulb and collision plate

According to the contact theory of "Solids of revolution" proposed by Hertz, the contact area is regarded as the approximate circle with the radius of $a$, and the radius of bulb $r$ is much larger than $a$. Hertz contact constitutive model can be expressed as ${ }^{[28]}$.

The radius of contact circle is 


$$
a=\sqrt[3]{\frac{3 F R}{4 E^{*}}}
$$

The total compression of the bulb and the collision plate is

$$
\delta=\delta_{1}+\delta_{2}=\frac{a^{2}}{R}
$$

The contact force between the bulb and the collision plate is

$$
F=-m \frac{\mathrm{d}^{2} \delta}{\mathrm{d} t^{2}}
$$

where, $a$ is the radius of contact circle, $\mathrm{m} ; \delta$ is the total compression of the bulb and the collision plate, $\mathrm{m} ; \delta_{1}$ and $\delta_{2}$ are the compression of the bulb and the collision plate, respectively, $\mathrm{m} ; R$ is the equivalent relative radius of curvature, $\mathrm{m} ; 1 / R=1 / R_{1}+1 / R_{2}, R_{1}$ and $R_{2}$ are the curvature radius of the bulb and the collision plate in the contact area, respectively, $\mathrm{m} ; E^{*}$ is equivalent elastic modulus, $\mathrm{Pa} ; 1 / E^{*}=\left(1-\mu_{1}^{2}\right) / E_{1}+\left(1-\mu_{2}^{2}\right) / E_{2}, E_{1}$ and $E_{2}$ are the elastic modulus of the bulb and the collision plate, respectively, $\mathrm{Pa} ; \mu_{1}$ and $\mu_{2}$ are the Poisson's ratio of the bulb and the collision plate, respectively; $m$ is equivalent mass, $\mathrm{kg} ; 1 / m=1 / m_{1}+1 / m_{2}, m_{1}$ and $m_{2}$ are the mass of the bulb and the collision plate, respectively, $\mathrm{kg} ; F$ is the contact force between the bulb and the collision plate, $\mathrm{N}$.

As $R_{2}$ is much larger than $R_{1}, R$ is approximately equal to $R_{1}$. From Equations (1) and (2), there is

$$
F=\frac{4}{3} R_{1}^{\frac{1}{2}} \delta^{\frac{3}{2}}\left(\frac{1-\mu_{1}^{2}}{E_{1}}+\frac{1-\mu_{2}^{2}}{E_{2}}\right)^{-1}
$$

As $m_{2}$ is much larger than $m_{1}, m$ is approximately equal to $m_{1}$. From Equations (3) and (4), there is

$$
-m_{1} \frac{\mathrm{d}^{2} \delta}{\mathrm{d} t^{2}}=\frac{4}{3} R_{1}^{\frac{1}{2}} \delta^{\frac{3}{2}}\left(\frac{1-\mu_{1}^{2}}{E_{1}}+\frac{1-\mu_{2}^{2}}{E_{2}}\right)^{-1}
$$

The friction of contact surface is negligible. It is considered that only contact force does work during collision. When the compression of the bulb and the collision plate reaches $\delta_{\max }$, the contact force reaches the maximum value, and the kinetic energy of the bulb and the collision plate is absorbed by the elastoplastic deformation $^{[28,29]}$, there is

$$
\frac{1}{2} m_{1} v_{0}^{2}=\int_{0}^{\delta_{\max }} F \mathrm{~d} \delta=\eta F_{\max } \delta_{\max }
$$

where, $v_{0}$ is the relative velocity of the bulb and the collision plate at initial collision, $\mathrm{m} / \mathrm{s} ; \eta$ is the bulb absorption coefficient of collision energy ${ }^{[29]}$.

$\delta_{\max }$ can be obtained from Equations (4) and (6) as:

$$
\delta_{\max }=\sqrt[5]{\frac{3}{8 \eta R_{1}^{1 / 2}}} \frac{\left.\frac{3 m_{1} v_{0}^{2}}{E_{1}}+\frac{1-\mu_{2}^{2}}{E_{2}}\right)}{2}
$$

Then, the maximum contact force can be obtained from Equations (4) and (7) as:

$$
F_{\max }=\frac{4}{3} R_{1}^{\frac{1}{2}} \delta_{\max }^{\frac{3}{2}}\left(\frac{1-\mu_{1}^{2}}{E_{1}}+\frac{1-\mu_{2}^{2}}{E_{2}}\right)^{-1}
$$

By applying double integration to Equation (5), the contact time of compression can be obtained as:

$$
t=\int_{0}^{\delta} \frac{\sqrt{15 m_{1}} \mathrm{~d} \delta}{\sqrt{15 m_{1} v_{0}{ }^{2}-16 R_{1}^{\frac{1}{2}} \delta^{\frac{5}{2}}\left(\frac{1-\mu_{1}^{2}}{E_{1}}+\frac{1-\mu_{2}{ }^{2}}{E_{2}}\right)^{-1}}}
$$

\section{Materials and methods}

\subsection{Materials}

"Jin Garlic", as an important variety of garlic in China was broadly planted in Jinxiang, Shandong, (Chinese core garlic-planting area), and its bulbs were taken as research object in this study. The coordinate system and dimensions of garlic bulb are shown in Figure 3. The diameter of bulb $D$ is $46-75 \mathrm{~mm}$, and the height $H$ is $36-56 \mathrm{~mm}$. The garlics used in the experiment were harvested manually. The stems and roots were cut. Surface soil was cleaned. Bulbs without pests and damage, and having small differences in diameter were selected. Some bulbs were stored at temperature of $-1{ }^{\circ} \mathrm{C}$ to $3^{\circ} \mathrm{C}$ and relative humidity of $50 \%$ to $60 \%$ for standby, and some bulbs were placed in ventilated and dry environment.

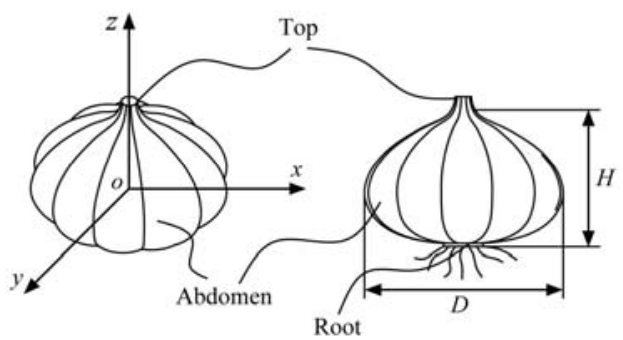

Note: $O-x y z$ is the space rectangular coordinate system, in which the $z$-axis coincides with the bulb mandrel; $D$ is the diameter of the bulb, $\mathrm{mm} ; H$ is the height of the bulb, mm

Figure 3 Schematic of the garlic bulb

By observing a large number of damaged bulbs, it is found that the damage is concentrated in the abdomen of the bulb, and the damage of the top and roots is little. The damage of the abdomen is extensive since the epidermis of the bulb and its cloves are thin and tender. Therefore, an abdomen collision of the bulb was conducted in this study.

\subsection{Equipment and mensuration}

\subsubsection{Mensuration of moisture content}

The moisture content of garlic bulb was measured by using the electric blast drying oven (DGF30/7-IA, Nanjing Experimental Instrument Factory). Five selected bulbs were placed in an aluminum box before each test, and the total mass was weighed. The bulbs were continuously dried at $95^{\circ} \mathrm{C}$ for $20 \mathrm{~h}^{[30]}$. The total mass after drying was weighed to obtain the moisture content of bulbs.

\subsubsection{Video acquisition and processing}

Three methods are commonly used to record kinematics characteristics of particles collision, namely methods of acceleration sensing, audio sampling, and high-speed image sampling. The acceleration sensing method is an indirect measurement and it requires sensors with high resolution ${ }^{[27,31]}$, and its errors of data processing are high. The audio sampling method has acceptable sampling accuracy, but it is impossible to observe the collision process intuitively. The high-speed image sampling method has high sampling accuracy, and the kinematics characteristics of bulb collision can be analyzed by means of visual image technology ${ }^{[15,32]}$.

The high-speed photography system (Fastec HiSpec 5, Fastec Imaging Co., Ltd) was used to record the deformation process of the bulb and the collision plate in this study, and extracted the time interval between the pop-up moment and the moment of loading on the sand table after the collision. The resolution of the CMOS detector was $1696 \times 1710$ pixels, the control software was HiSpec, the shooting frame frequency was 550 frames/s, and the exposure time was $1695 \mu \mathrm{s}$. Motion analysis software ProAnalyst (Xcitex Inc.) was used to process the video to obtain the bulb rotation angle and the bulb displacement curve. In this study, the feature points of the bulb were automatically captured frame by frame by 
ProAnalyst. The bulb rotation angle is the angle between the line connecting the two feature points of the bulb at the moment of initial collision and the line connecting the two feature points of the bulb at the current moment. The connecting line of feature points of the bulb of each frame is the bulb displacement curve.

\subsubsection{Experimental system}

The test of RC was performed on a homemade test platform, as shown in Figure 4. The test platform was mainly composed of a height pole, a support bevel for collision material, a positioning sand table, high-speed digital video camera, light source, calibration wall, etc. The xoy plane was vertical and the $z$-axis was parallel to the support bevel. The view-projection plane was parallel to the xoy plane.

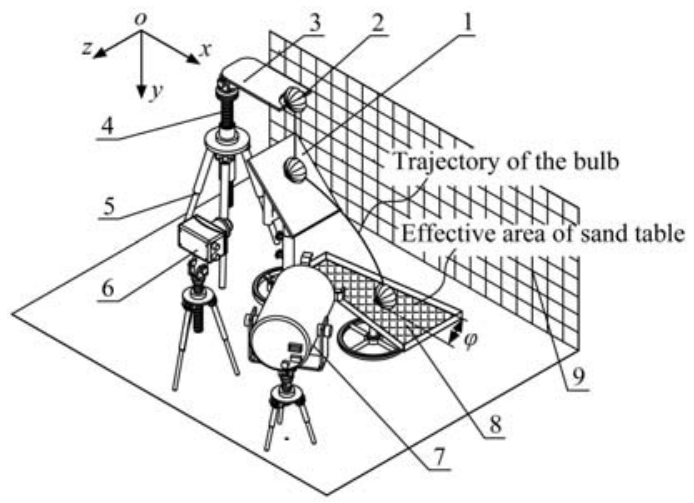

1. Support bevel for collision material 2. Placement hole 3. Horizontal ruler 4. Height pole 5. Tripod 6. High-speed digital video camera 7. Light source 8. Positioning sand table 9. Calibration wall

Note: $\varphi$ is the deflection angle of the effective area of the sand table, $\left(^{\circ}\right)$.

Figure 4 Test system for RC of garlic bulb

During the test, the bulb was released with an initial velocity $0 \mathrm{~m} / \mathrm{s}$ at the placement hole. The bulb hit the collision material on the support bevel, and a parabola was formed after the rebound. The inclination of the support bevel was set as $45^{\circ}$. The collision material was closely fitted to the support bevel with fastening pliers to eliminate the vibration caused by the gap or the loosening of the collision material. The bulb was placed by hand to ensure that the abdomen of the bulb collided with collision material. Due to deviation of the center of gravity of the bulb and manual placement, the trajectory plane of bulb might laterally deflect from the view-projection plane after the collision. The landing point was valid if it was located in the effective area of sand table, namely deflection angle $\varphi<5^{\circ}$.

\subsubsection{Experimental principle}

According to Newton's definition ${ }^{[33]}, \mathrm{RC}$ is the ratio of the rebound normal velocity after a collision to the approaching normal velocity before the collision. The bulb was free-falling before collision and oblique projectile moving after collision. The kinematics principle can be used to obtain the incidence velocity and reflection velocity of the bulb. Figure 5 shows a schematic diagram of the RC test.

As shown in Figure 5a, in order to avoid the deviation caused by the diameters difference of garlic bulbs, the lowest point $M$ of the bulb abdomen was regarded as the theoretical calculation basis in the test. Before release, the vertical displacement $h_{1}$ from the lowest point $M$ to hit point $O$, and the vertical displacement $h_{2}$ (set to $0.6 \mathrm{~m}$ ) from hit point $O$ to landing point $N$ was calibrated. After release, the horizontal displacement $S$ from hit point $O$ to landing point $N$ was determined, and the high-speed photography system was used to extract the time interval $t$.
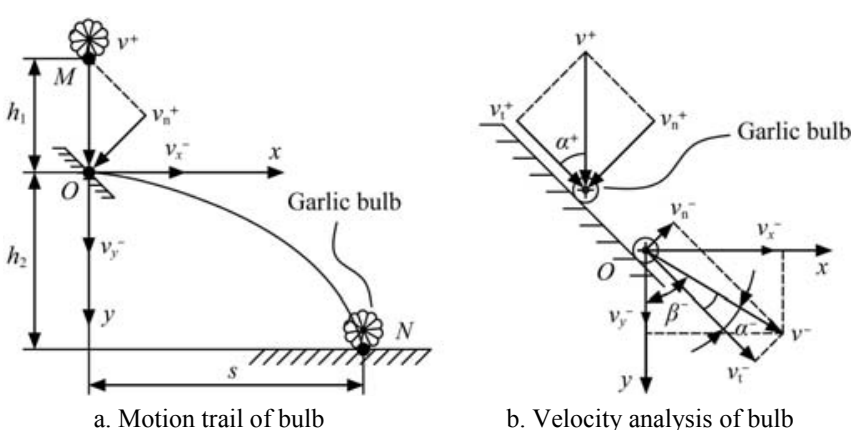

b. Velocity analysis of bulb

Note: $O$ is the hit point of collision, which is set as the origin of the coordinate system xoy; $M$ is the lowest point of the bulb abdomen; $N$ is the landing point of the bulb on the sand table; $h_{1}$ is the vertical displacement from point $M$ to point $O, \mathrm{~m} ; h_{2}$ is the vertical displacement from point $O$ to point $N, \mathrm{~m} ; S$ is the horizontal displacement from point $O$ to point $N, \mathrm{~m} ; v_{x}{ }^{-}$is the horizontal velocity of $v^{-}, \mathrm{m} / \mathrm{s} ; v_{y}{ }^{-}$is the vertical velocity of $v^{-}, \mathrm{m} / \mathrm{s} ; \beta$ is the angle between $v^{-}$and $y$, $\left({ }^{\circ}\right)$

Figure 5 Schematic diagram of the RC test

As shown in Figure 5a, the bulb is released from point $M$ with an initial velocity of $0 \mathrm{~m} / \mathrm{s}$. While air resistance is ignored, the incidence velocity of the bulb before collision can be expressed as:

$$
v^{+}=\sqrt{2 g h_{1}}
$$

where, $v^{+}$is the incidence velocity of the bulb, $\mathrm{m} / \mathrm{s} ; g$ is the acceleration of gravity, $\mathrm{m} / \mathrm{s}^{2} ; h_{1}$ is the vertical displacement from point $M$ to point $O, \mathrm{~m}$.

As shown in Figure 5b, the instantaneous reflection velocity $v$ is decomposed into horizontal velocity $v_{x}{ }^{-}$and vertical velocity $v_{y}{ }^{-}$. All of the displacement and velocity parameters here are considered as vectors. There are expressions as:

$$
\begin{gathered}
S=v_{x}{ }^{-} t \\
h_{2}=v_{y}{ }^{-} t+\frac{1}{2} g t^{2}
\end{gathered}
$$

From Equations (11) and (12), the horizontal velocity and vertical velocity can be calculated as:

$$
\left\{\begin{array}{l}
v_{x}{ }^{-}=S / t \\
v_{y}{ }^{-}=\left(h_{2}-\frac{1}{2} g t^{2}\right) / t
\end{array}\right.
$$

where, $v_{x}^{-}$is the horizontal velocity of $v^{-}, \mathrm{m} / \mathrm{s} ; v_{y}^{-}$is the vertical velocity of $v^{-}, \mathrm{m} / \mathrm{s} ; t$ is the time interval for the moving of bulb from point $O$ to point $N$, s; $S$ is the horizontal displacement from point $O$ to point $N, \mathrm{~m} ; h_{2}$ is the vertical displacement from point $O$ to point $N$, and the value is set as $0.6 \mathrm{~m}$.

The reflection angle can be expressed as:

$$
\begin{gathered}
\alpha^{-}=\beta^{-}-\pi / 4 \\
\beta^{-}=\arctan \left(v_{x}^{-} / v_{y}^{-}\right) \quad\left(-\pi / 2<\beta^{-}<\pi / 2\right)
\end{gathered}
$$

The normal velocity can be expressed as:

$$
v_{\mathrm{n}}^{-}=v^{-}\left|\sin \alpha^{-}\right|=\sqrt{\left(v_{x}^{-}\right)^{2}+\left(v_{y}^{-}\right)^{2}}\left|\sin \alpha^{-}\right|
$$

Then, from Equations (10)-(16), the RC of the bulb can be expressed as:

$$
e=\frac{v_{\mathrm{n}}^{-}}{{v_{\mathrm{n}}}^{+}}=\frac{\sqrt{\left(v_{x}^{-}\right)^{2}+\left(v_{y}^{-}\right)^{2}}\left|\sin \alpha^{-}\right|}{v^{+} \sin \alpha^{+}}
$$

where, $e$ is the $\mathrm{RC}$ of the bulb; $\beta$ is the angle between $v^{-}$and $y,\left(^{\circ}\right.$ ); $\alpha^{+}$is the incidence angle, $\left({ }^{\circ}\right) ; \alpha^{-}$is the reflection angle, $\left({ }^{\circ}\right) ; v^{-}$is the reflection velocity, $\mathrm{m} / \mathrm{s} ; v_{\mathrm{n}}{ }^{-}$is the normal velocity of $v^{-}, \mathrm{m} / \mathrm{s} ; v_{\mathrm{n}}{ }^{+}$is the normal velocity of $v^{+}, \mathrm{m} / \mathrm{s}$. 


\subsection{Test design}

The RC of bulbs is not only related to their own physical characteristics but also related to factors such as collision materials and incidence velocity. The effect of bulb mass $X_{1}$, moisture content $X_{2}$, collision material $X_{3}$, material thickness $X_{4}$, and release height $X_{5}$ (i.e., incidence velocity) on the RC of bulb were investigated in this study. The collision materials were selected from the common contact materials of garlic process equipment: steel plate Q235, rubber plate, nylon plate. The thickness of the plate was $1 \mathrm{~mm}, 3 \mathrm{~mm}, 5 \mathrm{~mm}$ respectively; the incidence velocity was achieved by different release heights, namely $100 \mathrm{~mm}$, $200 \mathrm{~mm}$ and $300 \mathrm{~mm}$. The moisture contents were $82.5 \%$ w.b., $69.3 \%$ w.b., and $61.6 \%$ w.b., respectively. They were measured on the day of harvest, after $3 \mathrm{~d}$ and $5 \mathrm{~d}$ airing and drying. In terms of bulb mass, for its randomness, a certain mass cannot be selected in the actual test. The selected range of $m_{1}(61 \pm 1 \mathrm{~g})$ and $m_{2}(45 \pm$ $1 \mathrm{~g}$ ) were regarded as the mass level of the bulb in the test.

Orthogonal tests were conducted for the above factors to determine the significant level of various factors that affected the $\mathrm{RC}$ and their sequence. The influencing factors and levels were shown in Table 1 . The $\mathrm{L}_{18}\left(2 \times 3^{7}\right)$ orthogonal table was selected, as shown in Table 2. Three replications were conducted for each test number, and the mean value of $\mathrm{RC}$ resulted from these replications was applied for the statistics analysis by IBM SPSS Statistics $22^{[34]}$.

Table 1 Influencing factors and levels

\begin{tabular}{lccc}
\hline \multirow{2}{*}{ Factors } & \multicolumn{3}{c}{ Level } \\
\cline { 2 - 4 } & 1 & 2 & 3 \\
\hline Bulb mass $X_{1} / \mathrm{g}$ & $61 \pm 1$ & $45 \pm 1$ \\
Moisture content $X_{2} / \%$ w.b. & 61.6 & 69.3 & 82.5 \\
Collision material $X_{3}$ & $\mathrm{Q} 235$ & rubber & nylon \\
Material thickness $X_{4} / \mathrm{mm}$ & 1 & 3 & 5 \\
Release height $X_{5} / \mathrm{mm}$ & 100 & 200 & 300 \\
\hline
\end{tabular}

Table 2 Experimental arrangement and results

\begin{tabular}{|c|c|c|c|c|c|c|}
\hline $\begin{array}{c}\text { Test } \\
\text { number }\end{array}$ & $\begin{array}{c}\text { Bulb } \\
\text { mass } \\
X_{1}\end{array}$ & $\begin{array}{c}\text { Moisture } \\
\text { content } \\
X_{2}\end{array}$ & $\begin{array}{c}\text { Collision } \\
\text { material } \\
X_{3}\end{array}$ & $\begin{array}{c}\text { Material } \\
\text { thickness } \\
X_{4}\end{array}$ & $\begin{array}{c}\text { Release } \\
\text { height } \\
X_{5}\end{array}$ & $\begin{array}{c}\mathrm{RC} \\
e\end{array}$ \\
\hline 1 & 1 & 1 & 1 & 1 & 1 & 0.653 \\
\hline 2 & 1 & 1 & 2 & 2 & 2 & 0.391 \\
\hline 3 & 1 & 1 & 3 & 3 & 3 & 0.431 \\
\hline 4 & 1 & 2 & 1 & 1 & 2 & 0.615 \\
\hline 5 & 1 & 2 & 2 & 2 & 3 & 0.319 \\
\hline 6 & 1 & 2 & 3 & 3 & 1 & 0.550 \\
\hline 7 & 1 & 3 & 1 & 2 & 1 & 0.689 \\
\hline 8 & 1 & 3 & 2 & 3 & 2 & 0.334 \\
\hline 9 & 1 & 3 & 3 & 1 & 3 & 0.533 \\
\hline 10 & 2 & 1 & 1 & 3 & 3 & 0.583 \\
\hline 11 & 2 & 1 & 2 & 1 & 1 & 0.459 \\
\hline 12 & 2 & 1 & 3 & 2 & 2 & 0.553 \\
\hline 13 & 2 & 2 & 1 & 2 & 3 & 0.559 \\
\hline 14 & 2 & 2 & 2 & 3 & 1 & 0.423 \\
\hline 15 & 2 & 2 & 3 & 1 & 2 & 0.586 \\
\hline 16 & 2 & 3 & 1 & 3 & 2 & 0.638 \\
\hline 17 & 2 & 3 & 2 & 1 & 3 & 0.428 \\
\hline 18 & 2 & 3 & 3 & 2 & 1 & 0.575 \\
\hline$k_{1}$ & 0.502 & 0.517 & 0.623 & 0.546 & 0.558 & \\
\hline$k_{2}$ & 0.534 & 0.509 & 0.392 & 0.514 & 0.520 & \\
\hline$k_{3}$ & & 0.533 & 0.538 & 0.493 & 0.476 & \\
\hline Range & 0.032 & 0.024 & 0.231 & 0.053 & 0.082 & \\
\hline
\end{tabular}

Note: $k_{1}-k_{3}$ are the mean values of the sum of RC at each level.

\section{Results and analysis}

\subsection{High-speed image analysis}

In order to study the kinematics characteristics and contact damage during bulb collision, the movement behavior of bulb, the elastoplastic deformation of bulb and generation process of garlic damage were recorded by high-speed photography ${ }^{[35-37]}$. The high-speed images of test No.2 in Table 2 were analyzed. Figure $6 \mathrm{a}$ is the moment when the bulb is in contact with the collision material, Figure $6 \mathrm{~b}$ is the moment when the velocity of the bulb is 0 , Figure $6 \mathrm{c}$ is the moment when the bulb left the collision material, and Figure $6 \mathrm{~d}$ is a moment after leaving the collision material. The blue dotted line is the line connecting the two feature points of the bulb at the moment of initial collision, as well as the yellow dotted line is the line connecting the two feature points of the bulb at the current moment.

Before collision, the bulb fell vertically downward with uniform acceleration, without angular velocity. At the moment of the collision, a garlic clove was in contact with the collision material (Figure 6a). Subsequently, compression deformation occurred (Figure 6b). The adjacent garlic clove on the left side also deformed gradually due to contact with the collision material. At this time, the bulb was subjected to squeezing force, friction, and gravity. The resultant force drove the bulb to rotate (Figure 6c). Finally, the bulb left the collision material, performed a parabolic motion and continued to fall with rotation (Figure 6d). Therefore, the kinematics behavior during bulb collision included deformation, translation, and rotation around the center of gravity.
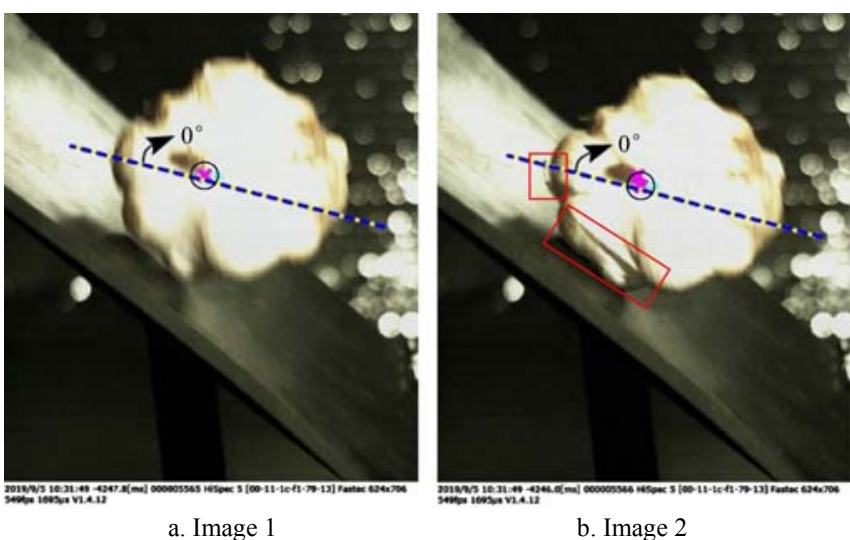

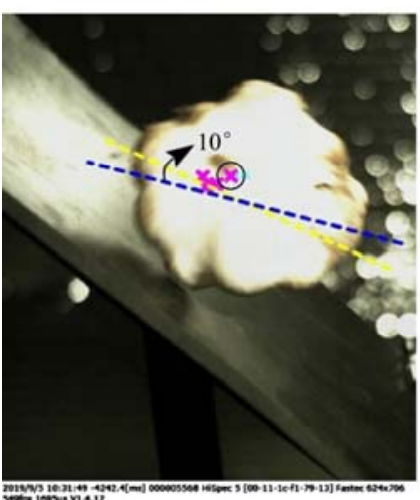

c. Image 3

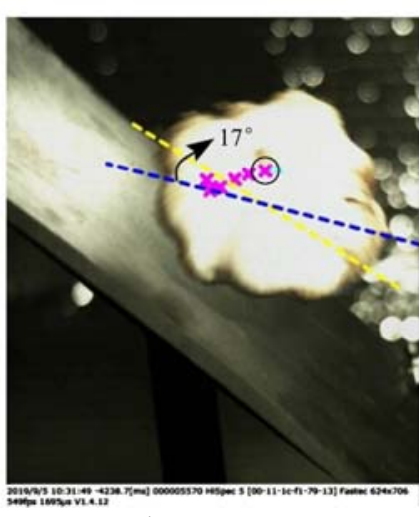

d. Image 4
Note: The pink crosses $\times$ represented the feature points of bulb stalks.

Figure 6 High-speed images of bulb collision process

As can be seen from Figure 6, the collision damage of the bulb mainly consisted of three parts. Firstly, the internal damage of the tissue, which was caused by the compression at the collision point. Secondly, after one garlic clove was compressed by the collision 
material, there was movement tend towards the center of gravity of the bulb, which caused the extrusion among the adjacent garlic cloves and caused their internal damage of the tissue. Thirdly, the epidermis of bulb was affected by the compression deformation of the garlic clove, and the epidermis was stretched and torn, as shown in the red frames in Figure 6b.

By comparing the positions of feature points of bulb stalks in Figures $6 \mathrm{a}$ and $6 \mathrm{~b}$, it can be concluded that when a bulb contacted the collision material, the feature point of the bulb stalk continued to move downward for a certain distance until the velocity dropped to $0 \mathrm{~m} / \mathrm{s}$. The distance was the vertical compression of the bulb. While the velocity of bulb dropped to $0 \mathrm{~m} / \mathrm{s}$, the feature point of the bulb stalk fell to the lowest point. At this time, the bulb underwent the maximum compression deformation, and the translational kinetic energy of the bulb was completely converted into elastic and plastic strain energy.

By comparing Figure $6 \mathrm{~b}$ with Figure $6 \mathrm{c}$, it can be concluded that when the feature point of the bulb stalk fell to the lowest point, the stored elastic strain energy gradually released and completely converted into translational and rotational kinetic energy of the bulb. The bulb moved obliquely upward, and the deformation of the bulb gradually recovered at the same time. The plastic strain energy caused irreversible plastic deformation of the bulb, which led to energy dissipation. Subsequently, the bulb detached from the collision material, and continued to move obliquely along the parabolic for a period of time. The move might be upward first, and then downward.

Before the collision, the bulb was free-falling without self-rotation. There was only translational energy. As can be seen from Figure 6a, Figure $6 \mathrm{~b}$ and Section 2.1, in compression stage, when the contact force reached the maximum value, the compression deformation of the bulb continued to increase, so the bulb did not rotate. As can be seen from Figures $6 \mathrm{~b}$ and $6 \mathrm{c}$, in the rebound stage, the bulb moved in the opposite direction, the compression decreased gradually, and the bulb rotated at the same time. As can be seen from Figures $6 \mathrm{c}$ and $6 \mathrm{~d}$, the bulb rotated obviously after the bulb detached from the collision material. Therefore, the movement of the bulb included translation and rotation around the center of gravity during the collision and after the bulb detached from the collision material. There were few reports on the study of rotation behavior of particle collision in previous studies ${ }^{[14,38]}$. High-speed images can be used to analyze the rotation of bulb intuitively. The effects of various factors on the $\mathrm{RC}$ in combination with the rotation of bulb were studied in the following section.

During the entire process of deformation of the bulb, there was no obvious relative sliding. Therefore, the friction between the bulb and the collision material was mainly static friction.

The results of high-speed image analysis were consistent with the theoretical analysis results in Section 2.

\subsection{Analysis of orthogonal experiment}

The range analysis of orthogonal experiment is shown in Table 2. The results showed that the significant level of various factors that affected the RC and their sequence was collision material, release height, material thickness, bulb mass, and moisture content. The variance analysis of orthogonal experiment was shown in Table 3. The results showed that within the scope of the $95 \%$ confidence coefficient, collision material and release height were extremely significant for the effect on RC, material thickness and bulb mass were significant, and moisture content was not significant.
Table 3 Variance analysis of orthogonal experiment

Factors Sum of squares Degree of freedom Mean squares $F$ value $p$ value

\begin{tabular}{cccccc}
\hline$X_{1}$ & 0.005 & 1 & 0.005 & 5.648 & 0.045 \\
$X_{2}$ & 0.002 & 2 & 0.001 & 1.267 & 0.333 \\
$X_{3}$ & 0.163 & 2 & 0.082 & 99.263 & $2 \mathrm{E}-6$ \\
$X_{4}$ & 0.008 & 2 & 0.004 & 5.096 & 0.037 \\
$X_{5}$ & 0.021 & 2 & 0.010 & 12.495 & 0.003 \\
Error & 0.007 & 8 & 0.001 & & \\
\hline
\end{tabular}

Note: $p<0.01$ (Very significant), $0.01<p<0.05$ (Significant), $p>0.05$ (Not significant).

\subsection{Analysis of single-factor experiments}

From the results of orthogonal experiment, it can be concluded that collision material, release height, material thickness, and bulb mass were the significant factors that affected the RC of garlic bulb. In order to further clarify the significant factors that affected the kinematics characteristics and RC of bulb, the single factor experiment was conducted for the above-mentioned significant factors. The change rule of bulb rotation during the collision was analyzed and the regression equations were obtained. Nine replications were conducted for each single factor experiment. The RC of each experiment was determined respectively. The mean value of $\mathrm{RC}$ resulted from these replications was used to calculate regression equations. Due to the extreme significance of the collision material and the release height on the $\mathrm{RC}$, these two factors were focused on by the high-speed image analysis in this study.

\subsubsection{Collision material}

Q235, rubber, and nylon were selected as collision material. The material thickness of $3 \mathrm{~mm}$ was commonly used for garlic equipment, the bulb mass was $m_{1}(61 \pm 1 \mathrm{~g})$, and the release height was $200 \mathrm{~mm}$. The tests were carried out on the harvest day when the moisture content of the bulb was $82.5 \%$ w.b. The results of the single factor test were shown in Figure 7. The RCs between the bulb and Q235, nylon, and rubber decreased sequentially. The rubber material has buffering and vibration attenuation effect. Its strain energy stored in the compression stage was easily transmitted to the surroundings in the form of stress waves, which led to energy dissipation. Then, the strain energy transmitted to the bulb during the rebound stage reduced, and the kinetic energy of the bulb reduced. Therefore, the $\mathrm{RC}$ between the bulb and rubber was relatively small.

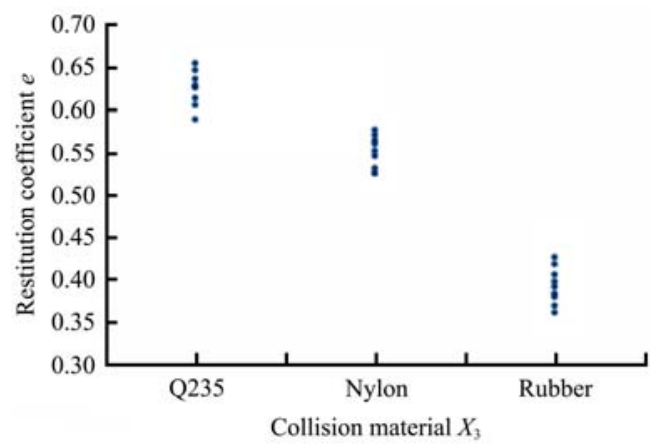

Figure 7 Effect of collision materials on RC

The movement of the bulb during the collision was shown in Figure 8. The moment of the initial collision was defined as the initial time of collision, and the first frame picture was set and captured. The moving images were captured every 4 frames with a time interval of $7.28 \mu \mathrm{s}$. As can be seen from Figure 8, at the same time interval, the rotation angle of the bulb was the largest when the collision material was rubber; the rotation angle was smallest when the collision material was Q235. By comparing the 
RCs between the bulb and the three materials, under the above-mentioned test conditions, during the collision, the larger the rotational angular velocity of bulb was, the smaller the measured $\mathrm{RC}$ between the bulb and collision materials would be. The possible reason was: during the collision, the lower the collision material hardness was, the smaller the micro-plastic deformation of the bulb would be, and the smaller the plastic strain energy of the bulb would be. Because the bulb mass and release height were constant in each test, the total energy of the bulb was the same during each collision. When the compression of the bulb was the largest, the relative velocity and angular velocity of bulb were $0 \mathrm{~m} / \mathrm{s}$, and the kinetic energy was 0 . The total energy of the bulb

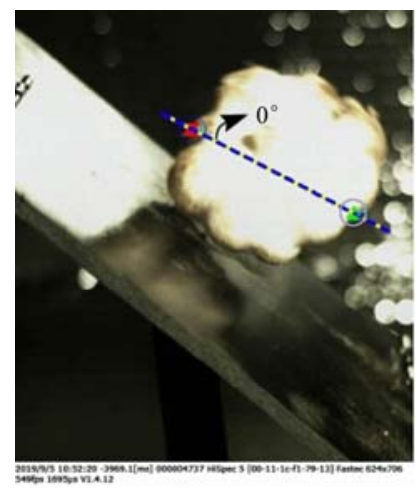

The 1st frame

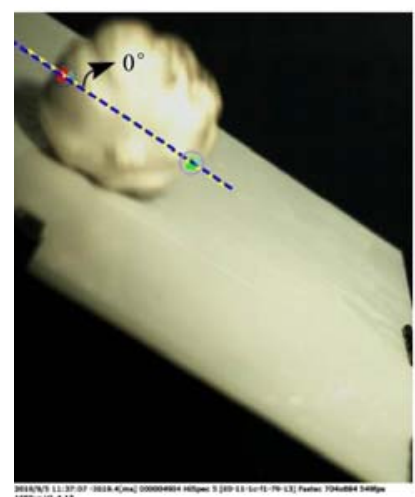

The 1st frame

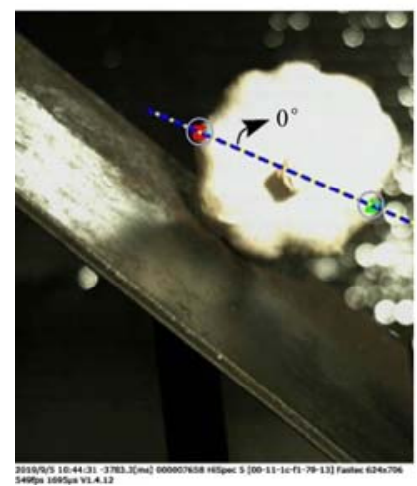

The 1st frame

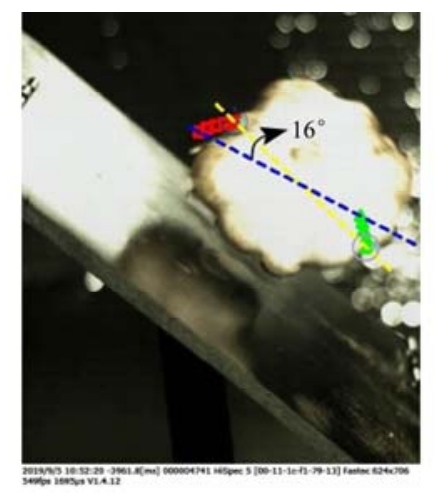

The 5th frame

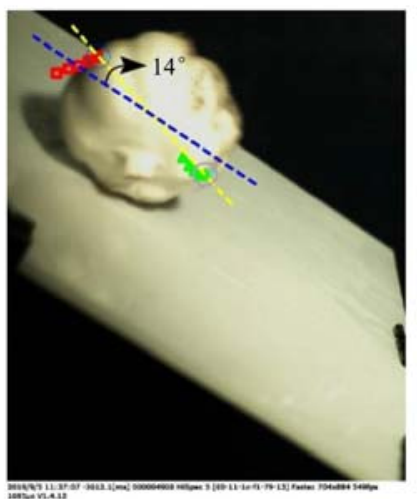

The 5 th frame

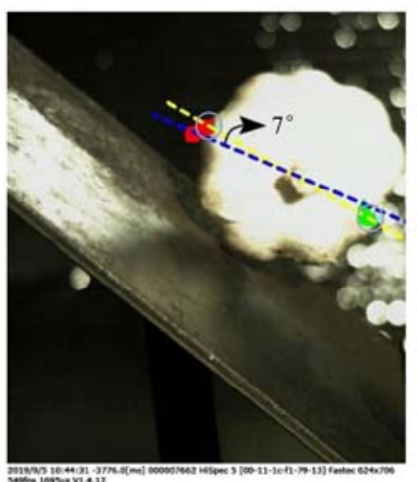

The 5 th frame

was equal to the sum of plastic strain energy and elastic strain energy. As the plastic strain energy decreased, the elastic strain energy increased. During the rebound stage, the elastic strain energy was completely converted into translational and rotational kinetic energy. Because RC between the bulb and rubber material was the smallest, the reflection velocity of the bulb and translational kinetic energy was the smallest, which resulted in the increase of rotational kinetic energy and angular velocity of the bulb. Therefore, in order to reduce collision damage or translational kinetic energy of the bulb after rebound, it's better to select rubber or materials with smaller $\mathrm{RC}$ as contact parts of the garlic equipment.

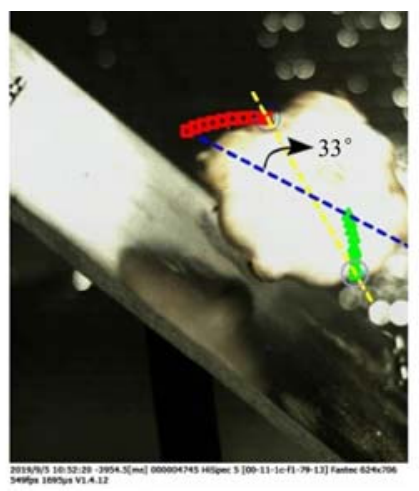

The 9th frame Rubber

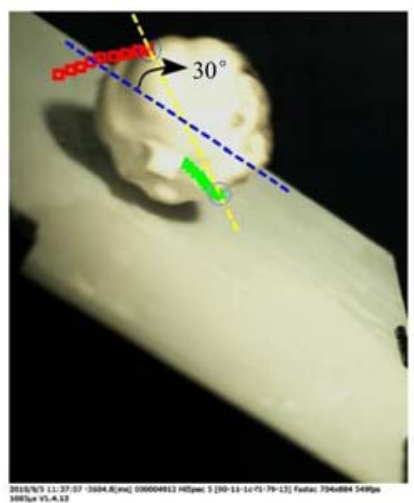

The 9th frame

b. Nylon

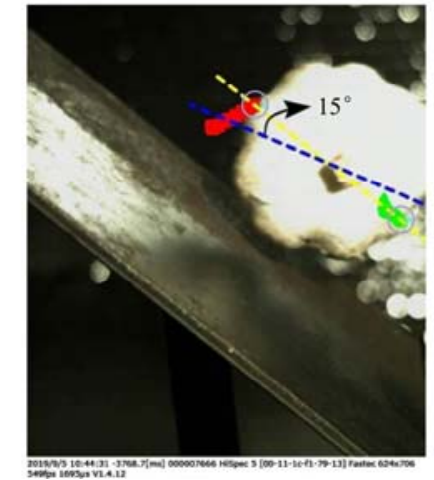

The 9th frame

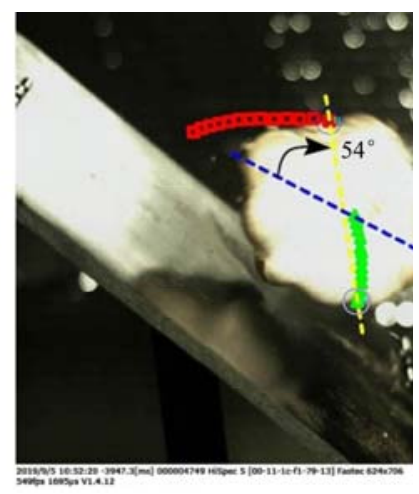

The 13th frame

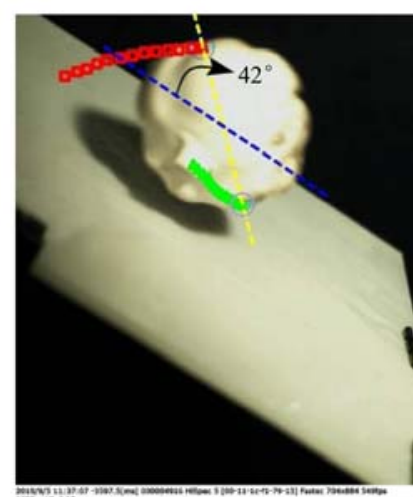

The 13th frame

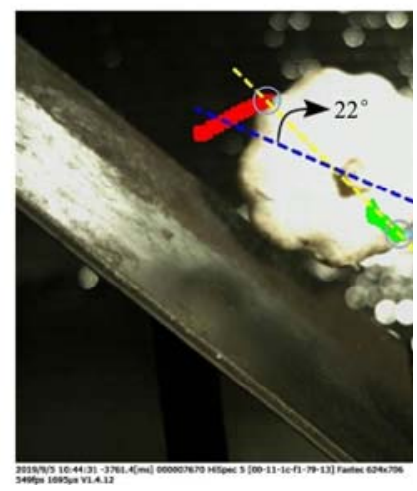

The 13th frame c. Q235

Note: The red $\square$ and green $\triangle$ represented feature points of the bulb.

Figure 8 High-speed images of the bulbs during the collision with different collision materials

\subsubsection{Release height}

The release heights of $100 \mathrm{~mm}, 200 \mathrm{~mm}, 300 \mathrm{~mm}, 400 \mathrm{~mm}$, and $500 \mathrm{~mm}$ were selected. Nylon is commonly used as the contact material of garlic processing equipment and it was selected as the collision material. The selections of material thickness, bulb mass, and moisture content were the same as that in Section 4.3.1. The results of the single factor test are shown in Figure 9. The RC of bulb decreased with the increase of the release height. The quadratic regression equation of the release height and the $\mathrm{RC}$ was obtained, $R^{2}=0.99$. The equation of $\mathrm{RC} e_{1}$ is 
$e_{1}=-0.000000786 X_{5}^{2}-0.000057 X_{5}+0.589$

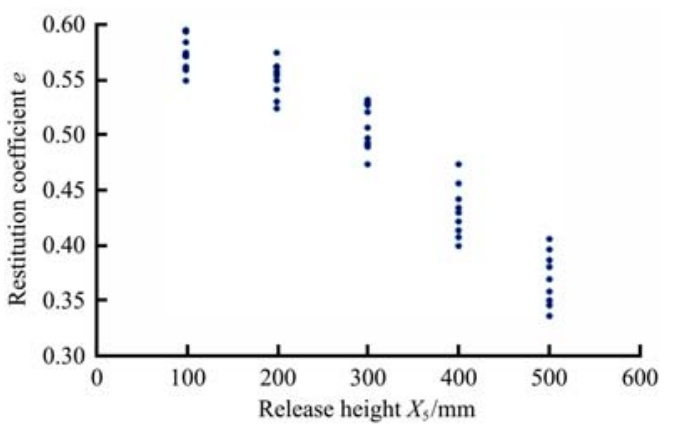

Figure 9 Effect of release height on $\mathrm{RC}$

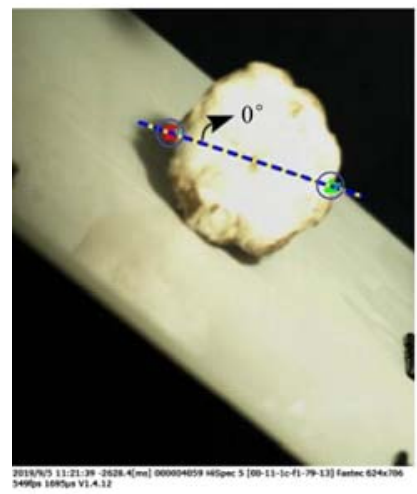

The 1st frame

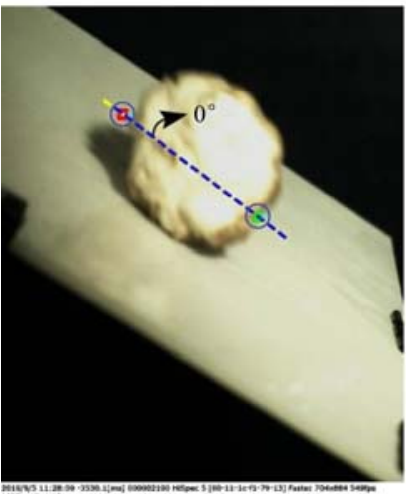

The 1st frame

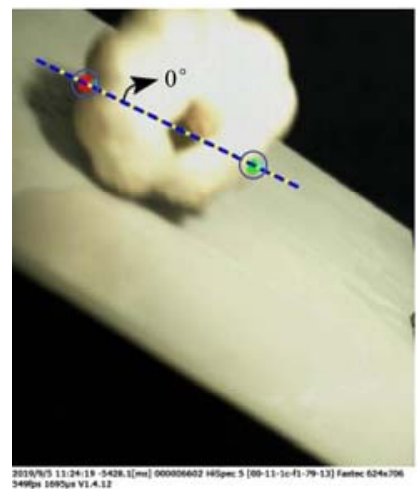

The 1st frame

The movement of the bulb during the collision is shown in Figure 10. As can be seen from Figure 10, at the same time interval, the higher the release height was, the larger the rotation angle of bulb would be. The possible reason was: the higher the release height was, the larger the impact force of the bulb on the collision materials would be, and the larger the reaction force on the bulb would be, which resulted that a couple of squeezing force, friction and gravity strengthened, and rotational angular velocity and the rotational kinetic energy of the bulb increased. By comparing Figures 9 and 10, under the above-mentioned test conditions, during the collision, the larger the rotational angular velocity of bulb was, the smaller the measured RC of bulb would be, which was consistent with the conclusion in Section 4.3.1.

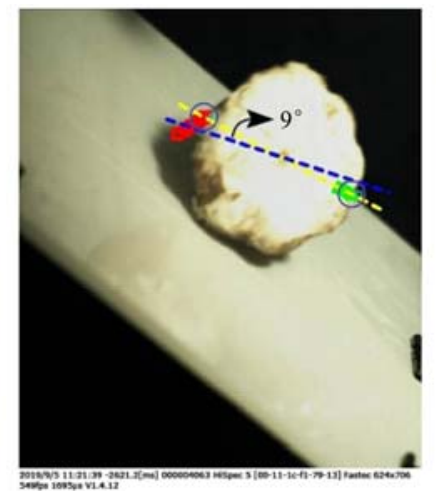

The 5 th frame

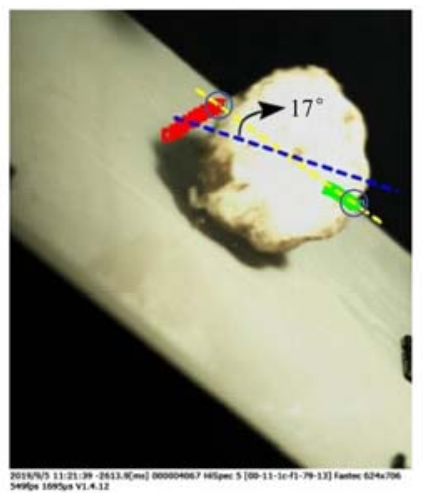

The 9th frame

a. Release height of $100 \mathrm{~mm}$

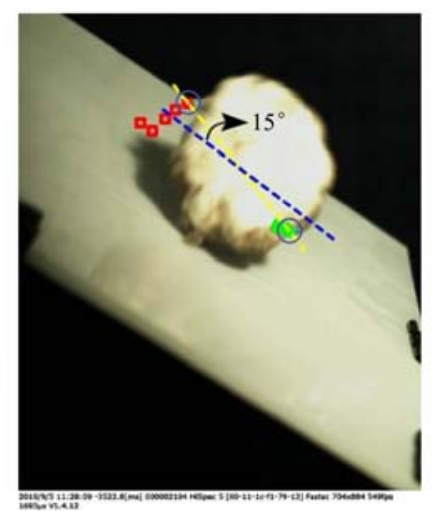

The 5 th frame

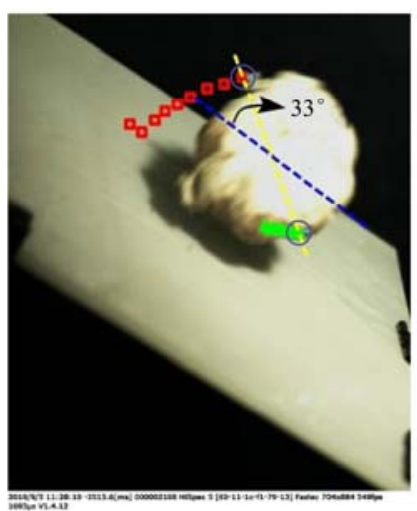

The 9th frame

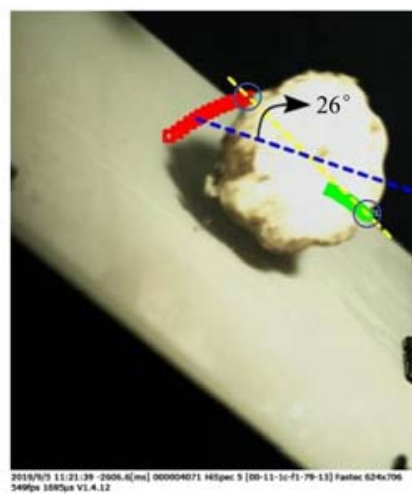

The 13th frame

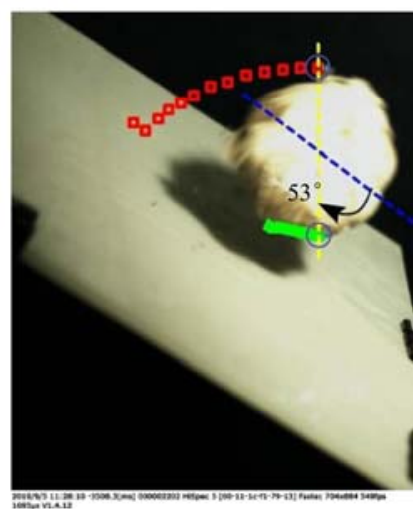

The 13th frame

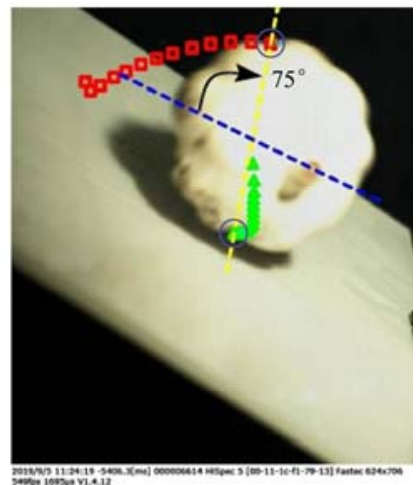

The 13th frame

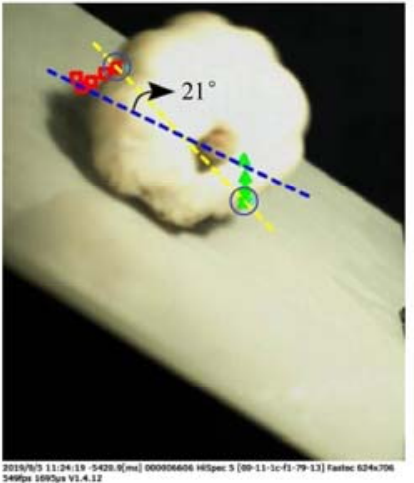

The 5 th frame

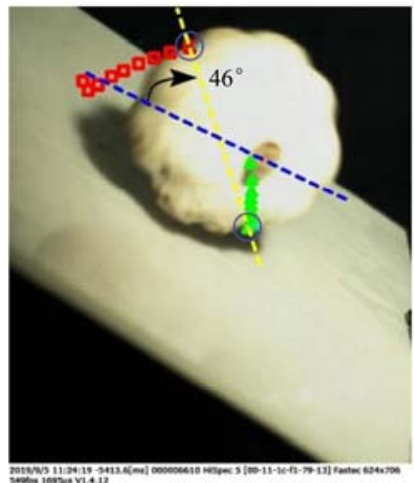

The 9th frame

c. Release height of $500 \mathrm{~mm}$

Figure 10 High-speed images of the bulbs during the collision at different release height

The higher the release height was, the larger the plastic deformation of the bulb and the frictional resistance between the bulb and collision materials would be, and the total energy dissipation during the collision increased significantly, which resulted that the RC decreased. In addition, the higher the release height was, the larger the incidence velocity would be, and the smaller the RC of bulb would be, which agreed with a conclusion from Mangwandi et al. ${ }^{[23]}$ Therefore, in order to reduce the 
collision damage of bulb caused by the contact with the garlic equipment, the height difference between the bulb and the collision materials should be mainly considered.

\subsubsection{Material thickness}

The effect of the material on the RC was related to the physical properties of the material, and these properties were affected by material type and material thickness. The effect of material thickness on the RC may be different for different materials. Therefore, single-factor tests were performed for the thicknesses effect of the three collision materials, namely, rubber, nylon, and Q235, with thicknesses of $1 \mathrm{~mm}, 3 \mathrm{~mm}, 5 \mathrm{~mm}, 7 \mathrm{~mm}$, and $9 \mathrm{~mm}$. The selections of release height, bulb mass, and moisture content were the same as that in Section 4.3.1. The results of the single factor tests are shown in Figure 11.

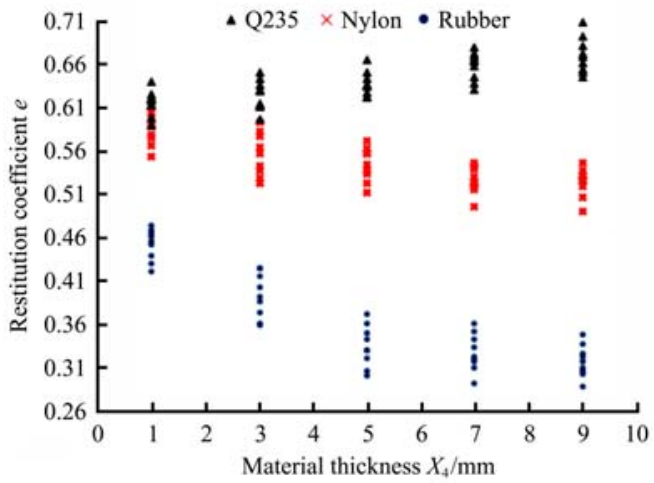

Figure 11 Effect of material thickness on RC

As shown in Figure 11, when the material was Q235, the RC of bulb increased with the increase of the material thickness. Since the stiffness of Q235 was related to the thickness, the rigidity increased with the increase of thickness, and the resistance of deformation increased during the collision. Since the deformation of Q235 relatively reduced, the energy dissipation reduced, and the $\mathrm{RC}$ increased. The quadratic regression equation of the thickness of Q235 and the RC was obtained, $R^{2}=0.99$. The equation of RC $e_{2}$ was

$$
e_{2}=0.000268 X_{4}^{2}+0.00457 X_{4}+0.609
$$

When the material was rubber or nylon, the $\mathrm{RC}$ of bulb decreased with the increase of the material thickness. While the thickness of rubber or nylon increased, the buffering and damping effect enhanced, then the strain energy was easily transmitted to the surroundings, and then the energy dissipation increased, which resulted in the decrease of RC with the increase of thickness of the rubber or nylon. The quadratic regression equations of $\mathrm{RC}$ with thickness of rubber and nylon were obtained as $e_{3}\left(R^{2}=0.99\right), e_{4}$ $\left(R^{2}=0.97\right)$, respectively, and they were expressed as:

$$
\begin{aligned}
& e_{3}=0.00264 X_{4}{ }^{2}-0.0043 X_{4}+0.492 \\
& e_{4}=0.000982_{4}{ }^{2}-0.0173 X_{4}+0.599
\end{aligned}
$$

In summary, in order to reduce the collision damage of bulb, a suitable material thickness should be selected according to different collision materials.

\subsubsection{Bulb mass}

Nylon was selected as the collision material, and $(45 \pm 1) \mathrm{g}$, $(53 \pm 1) \mathrm{g},(61 \pm 1) \mathrm{g},(69 \pm 1) \mathrm{g},(77 \pm 1) \mathrm{g}$ were selected as bulb mass. The selections of release height, material thickness, and moisture content were the same as that in Section 4.3.1. The results of the single factor experiments were shown in Figure 12. The RC of bulb decreased with the increase of the bulb mass. But the reduction was not significant. The quadratic regression equation of the bulb mass and the $\mathrm{RC}$ was obtained, $R^{2}=0.99$. The equation of $\mathrm{RC} e_{5}$ was

$$
e_{5}=-0.0000143_{1}^{2}+0.00116 X_{1}+0.531
$$

The greater the bulb mass was, the larger the inertial force generated by collision and the plastic deformation of the bulb would be, which resulted that the energy dissipation increased during the collision, then reflection velocity of bulb decreased, and then the $\mathrm{RC}$ decreased ${ }^{[26]}$.

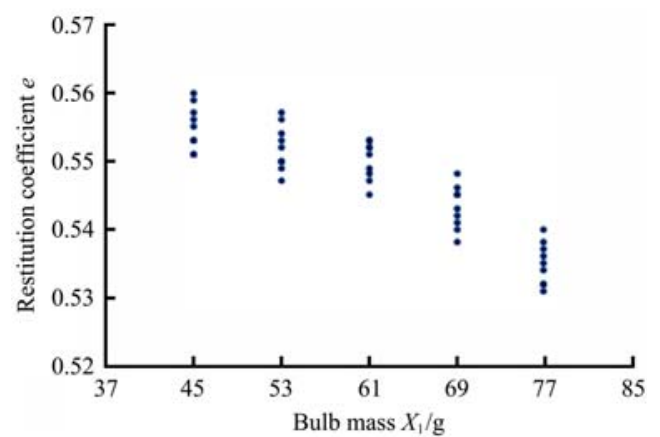

Figure 12 Effect of bulb mass on RC

\section{Discussion}

During the collision between the garlic bulb and the collision material, due to the irregular shape of the abdomen of the garlic bulb, the deviation of the geometric center and the center of gravity, there was a certain angle of deflection between the trajectory plane and the view-projection plane of the bulb after collision. In addition, some bulbs did not bounce directly after collision, instead of sliding against the collision material. All of the above phenomena may affect the accuracy of the test, and lead to deviations of the test data. In order to avoid the above problems, garlic bulbs with regular shapes were selected, and the high-speed images were used to exclude the test data with sliding or rolling of bulb along with the collision material. As such, only test data within a deflection angle of $5^{\circ}$ were considered for the statistical analysis. In the future, further research will be focused on the causes of deflection of the trajectory plane, the triaxial spatial trajectory of bulb after deflection, and the causes of the sliding or rolling of bulb along with the collision material.

\section{Conclusions}

(1) The kinetics equations of the maximum compression, the maximum contact force, the maximum contact stress, and the compression-contact time were established based on the Hertz contact theory. The RC expression for the garlic bulb was established based on Newton's definition.

(2) The kinematics behavior during bulb collision included deformation, translation, and rotation around the center of gravity. The movement of bulb in the compression stage was translation, while the movement in rebound stage was translation and rotation. When the contact force reached the maximum value, the compression deformation of bulb increased continuously until reached the maximum. The contact damage of bulb included internal damage of the tissue caused by the compression at the collision point and the extrusion among the adjacent garlic cloves, epidermis stretch and tear.

(3) According to range analysis and variance analysis, the significant sequence of various factors that affected the RC was collision material, release height, material thickness, bulb mass, and moisture content. Collision material and release height were extremely significant, material thickness and bulb mass were significant, and moisture content was not significant.

(4) According to the single-factor experiment, the larger the 
rotational angular velocity of bulb was, the smaller the measured $\mathrm{RC}$ would be. Q235 showed the highest RC, and it was followed by nylon and rubber sequentially; the RC decreased with the increase of release height and bulb mass; the RC increased with the increase of material thickness of Q235, while it decreased with the increase of material thickness of rubber or Nylon; regression equations between the significant factors and the RC were obtained, with determination coefficients greater than 0.96 .

\section{Acknowledgements}

This work was supported by the National Natural Science Foundation of China (Grant No. 51805282), Funds for Central Universities, China (XDJK2018AC001), and National Key R\&D Program of China (2017YFD0701305-02).

\section{[References]}

[1] Hou J L, Huang S H, Niu Z R, Wu Y Q, Li T H. Mechanism analysis and test of adjusting garlics upwards using two duckbill devices. Transactions of the CSAM, 2018; 49(11): 87-96. (in Chinese)

[2] Yu Z Y, Hu Z C, Yang K, Peng B L, Wu F, Xie H X. Design and experiment of root cutting device in garlic combine harvesting. Transactions of the CSAE, 2016; 32(22): 77-85. (in Chinese)

[3] Jones C S, Holt J E, Schoorl D. A model to predict damage to horticultural produce during transport. Journal of Agricultural Engineering Research, 1991; 4: 259-272.

[4] Opara U L, Pathare P B. Bruise damage measurement and analysis of fresh horticultural produce-A review. Postharvest Biology and Technology, 2014; 91: 9-24.

[5] Celik H K. Determination of bruise susceptibility of pears (Ankara variety) to impact load by means of FEM-based explicit dynamics simulation. Postharvest Biology and Technology, 2017; 128: 83-97.

[6] Du D D, Wang B, Wang J, Yao F Q, Hong X Z. Prediction of bruise susceptibility of harvested kiwifruit (Actinidia chinensis) using finite element method. Postharvest Biology and Technology, 2019; 152: 36-44.

[7] Zhu H P, Zhou Z Y, Yang R Y, Yu A B. Discrete particle simulation of particulate systems: a review of major applications and findings. Chemical Engineering Science, 2008; 63(23): 5728-5770.

[8] Zhang Z, Zhu R X. Finite element analysis and improving design of double-wing deep loosening shovel. Journal of Gansu Agricultural University, 2012; 47(1): 140-144. (in Chinese)

[9] Gao Y W, Song C B, Rao X Q, Ying Y B. Image processing-aided FEA for monitoring dynamic response of potato tubers to impact loading. Computers and Electronics in Agriculture, 2019; 151: 21-30.

[10] Ma Y H. Agricultural materials science. Beijing: Chemical Industry Press, 2015; 159p. (in Chinese)

[11] Wall S, John W, Wang H C, Simon L. Measurements of kinetic energy loss for particles. Aerosol Science Technology, 1990; 12(4): 926-946.

[12] Ding W L, Wan Z X, Xu Y, Max N. New collision detection method for simulating virtual plant populations. Int J Agric \& Biol Eng, 2019; 12(6): 156-161.

[13] Wang J W, Tang H, Wang J F, Jiang D X, Li X. Measurement and analysis of restitution coefficient between maize seed and soil based on high-speed photography. Int J Agric \& Biol Eng, 2017; 10(3): 102-114.

[14] Buck B, Tang Y L, Heinrich S, Deen N G, Kuipers J A M. Collision dynamics of wet solids: rebound and rotation. Powder Technology, 2017; 316: 218-224.

[15] Wang L J, Xu B X, Wu Z C, Li R, Feng X. Experimental determination of the coefficient of restitution of particle-particle collision for frozen maize grains. Powder Technology, 2018; 338: 263-273.

[16] Wang L J, Zheng Z H, Yu Y Y, Liu T H, Zhang Z H. Determination of the energetic coefficient of restitution of maize grain based on laboratory experiments and DEM simulations. Powder Technology, 2020; 362: 645-658.

[17] Qin Z Y, Lu Q S. Analysis of impact process model based on restitution coefficient. Journal of Dynamics and Control, 2006; 4(4): 294-298. (in Chinese)

[18] Dintwa E, Van Zeebroeck M, Ramon H, Tijskens E. Finite element analysis of the dynamic collision of apple fruit. Postharvest Biology and Technology, 2008; 49(2): 260-276.

[19] Aryaei A, Hashemnia K, Jafarpur K. Experimental and numerical study of ball size effect on restitution coefficient in low velocity impacts. International Journal of Impact Engineering, 2010; 37(10): 1037-1044.

[20] Wong C X, Daniel M C, Rongong J A. Energy dissipation prediction of particle dampers. Journal of Sound and Vibration, 2009; 319(1-2): 91-118.

[21] Marroquín F A, Gómez Á R, Montellano C G, Balaam N. Experimental and numerical determination of mechanical properties of polygonal wood particles and their flow analysis in silos. Granular Matter, 2013; 15: 811-826.

[22] Gómez Á R, Gallego E, Fuentes J M, Montellano C G, Ayuga F. Values for particle-scale properties of biomass briquettes made from agroforestry residues. Particuology, 2014; 12: 100-106.

[23] Mangwandi C, Cheong Y S, Adams M J, Salman A D. The coefficient of restitution of different representative types of granules. Chemical Engineering Science, 2007; 62(1-2): 437-450.

[24] Buzzi O, Giacomoni A, Spadari M. Laboratory investigation on high values of restitution coefficients. Rock Mechanics and Rock Engineering, 2012; 45: 35-43.

[25] Wang C J, Li Y M, Ma L Z, Ma Z. Experimental study on measurement of restitution coefficient of wheat seeds in collision models. Transactions of the CSAE, 2012; 28(11): 274-278. (in Chinese)

[26] Feng B, Sun W, Shi L R, Sun B G, Zhang T, Wu J M. Determination of restitution coefficient of potato tubers collision in harvest and analysis of its influence factors. Transactions of the CSAE, 2017; 33(13): 50-57. (in Chinese)

[27] Ye Y, Zeng Y W, Zeng C, Jin L. Experimental study on the normal restitution coefficient of granite spheres. Chinese Journal of Rock Mechanics and Engineering, 2017; 36(3): 633-643. (in Chinese)

[28] Johnson J K. Contact Mechanics. London: Cambridge University Press, 1985.

[29] Kanafojski C, Karwowski T. Corp-harvesting machines. Cao C W, Wu C J, Ke B K (Trans.). Beijing: China Agricultural Machinery Press, 1983. (in Chinese)

[30] Duan X, Liu W C, Ren Y, Yang X T, Liu Y H. Atmospheric freeze drying garlic slices based on freezing point depression. Int J Agric \& Biol Eng, 2015; 8(4): 133-139.

[31] Wang J, Ying T J, Cheng K C. Evaluation of pear firmness by dynamic characteristics of drop impact. Journal of the Science Food and Agriculture, 2007; 87(8): 1449-1454.

[32] Karayel D, Wiesehoff M, Özmerzi A, Müller J. Laboratory measurement of seed drill seed spacing and velocity of fall of seeds using high-speed camera system. Computers and Electronics in Agriculture, 2006; 50(2): 89-96.

[33] Ji Z M, Chen Z J, Niu Q H, Wang T J, Song H, Wang T H. Laboratory study on the influencing factors and their control for the coefficient of restitution during rock fall impacts. Landslides, 2019; 16(10): 1939-1963.

[34] Li X, Zhang M M. SPSS22.0 Statistical analysis from introduction to mastery. Beijing: Electronic Industry Press, 2015; 488p. (in Chinese)

[35] Celik H K, Rennie A E W, Akinci I. Deformation behaviour simulation of an apple under drop case by finite element method. Journal of Food Engineering, 2011; 104(2): 293-298.

[36] Gibson L M, Gopalan B G, Pisupati S V, Shadle L J. Image analysis measurements of particle coefficient of restitution for coal gasification applications. Powder Technology, 2013; 247: 30-43.

[37] Zhang Z, Heinemann P H, Liu J, Baugher T A, Schupp J R. The development of mechanical apple harvesting technology: A review. Transactions of the ASABE, 2016; 59(5): 1165-1180.

[38] Jiang Z C, Du J J, Rieck C, Bück A, Tsotsas E. PTV experiments and DEM simulations of the coefficient of restitution for irregular particles impacting on horizontal substrates. Powder Technology, 2020; 360: $352-365$. 